
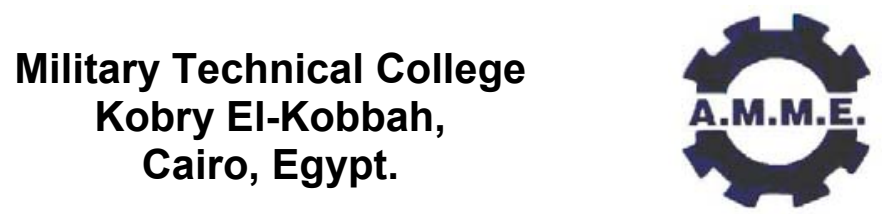

$13^{\text {th }}$ International Conference on Applied Mechanics and Mechanical Engineering.

\title{
THE EFFECT OF RIBS ON BEHAVIOR OF NATURAL GAS VEHICLE PLATFORM BACKBONE WITH STAMPING CONSIDERATION
}

\author{
SAHARI", B.B., ARSAD ${ }^{* *}$ N.M. \\ HAMOUDA $^{* * *}$ A.M.S., WONG ${ }^{* * *}$ S.V. and AHMAD ${ }^{* * * *}$ M.F.
}

\begin{abstract}
The platform is the basic automotive body structure. It is on this platform that engine and other components are attached. It is made by stamping of sheet metal. The main parts are the front and rear. Backbone made of stronger material is used to strengthen the platform. It is located in the central portion of the platform. For natural gas vehicle, a gas tank is placed underneath the backbone. The backbone is designed for high stiffness and ribs are used. The ribs may cause tearing during stamping. The objective of this paper is to determine the number of ribs that give high stiffness of the backbone without causing defect during stamping. Finite element is used. The backbone with 3 , 4 and 5 ribs was investigated. It was found that backbone with 3 ribs is sufficient for no failure during stamping. Backbone with 5 ribs shows through thickness crack during stamping.
\end{abstract}

\section{KEYWORDS}

Vehicle body platform backbone, metal stamping, finite element analysis, vehicle body platform, natural gas vehicle, through thickness crack failure.

\footnotetext{
Professor, Institute of Advanced Technology, ITMA, Universiti Putra Malaysia. Graduate student, Dpt. of Mech. and Manufacturing Engineering, Universiti Putra Malaysia.

*** $\quad$ Professor, Dpt. of Mechanical Engineering, Qatar University.

**** Associate Professor, Dpt. of Mech. and Manufacturing Engineering, Universiti Putra Malaysia.

***** Section Head, R and D, Perusahaan Otomobil Nasional Sdn Bhd (PROTON).
} 


\section{INTRODUCTION}

Automotive body is a complex structure. It consists of upper body and platform [1]. They are designed for strength, stiffness, crashworthiness and minimum weight [2,3]. The platform is further distinguished by the front and rear platform as shown in Fig. 1. Platforms are load carrying members. They are fabricated from sheet metal of thicknesses from as low as $0.3 \mathrm{~mm}$ to as high as $2.8 \mathrm{~mm}$. The most common process in platform parts fabrication is stamping [4, 5 and 6]. In addition to that, some parts are further reinforced for increase strength and crashworthiness. One of the reinforcement components of the front platform is the backbone. The detail construction of the front platform and the backbone is shown in Fig. 2. It is usually made of strongest material and the thickest among the platform sheets. The shape of the backbone is also unique in the sense that it has ribs for increase strength and also to conform to other parts such as the handbrake and gear levers attached to it. Hence, the backbone is more difficult to fabricate and if not designed properly, it can wrinkle, can undergo excessive thinning and finally leads to through thickness crack failure [6]. Torn backbone is undesirable and has to be avoided. Therefore, detail analysis on backbone during stamping need to be carried out and potential sources of defects could be identified and rectified. Stamping process analysis of other parts has been carried out by many researchers [4, 5, 7-9]. Finite element method has also been used in the analysis of stamping process by previous investigators [4,6]. However, analysis on the platform backbone is still scarce especially for the ribs.

In this paper, finite element method was used to simulate stamping process for automotive platform backbone. LSDYNA explicit elastic plastic finite element suite of program was used. Three types of backbone each with 3,4 and 5 ribs were investigated. The objective of the paper is to determine the suitable number of ribs to avoid failure due to through thickness crack. Maximum effective plastic strain criterion is used to determine the failure and the results were compared fabricated backbone with 5 ribs. The finite element results were then used to explain the reasons for backbone stamping failure.

\section{MATERIAL BEHAVIOR AND FAILURE CRITERIA}

The material used in the analysis is sheet steel, nominal thickness of $2.8 \mathrm{~mm}$. The properties were determined by testing a sample of the material and the stress plastic strain curve is shown in Fig. 3. From Fig. 3, it can be seen that, there is a small perfectly plastic region up to $0.05 \%$ plastic strain and thereafter the material hardens. There is no necking occurs prior to failure and failure occurs at $1 \%$ plastic strains. It could be said that the material is behaving plastically hardening with brittle failure. The values of Young's Modulus, E, Poisson's ratio and yield stress is given in Table 1 together with friction values for the stamping process simulation. The materials stress strain behaviour shown in Fig. 3 is used as material input data in LSDYNA software instead of modelling the plastic part of the curve. In the proceeding analysis, the material is assumed to be elastic plastic. The total strain $\varepsilon$ is given by:-

$$
\varepsilon=\varepsilon^{e}+\varepsilon^{p}
$$


where $\varepsilon^{e}$ and $\varepsilon^{p}$ are elastic and plastic strains respectively. The yield condition of the material is given by:-

$$
\sigma_{e q}=\sqrt{\frac{3}{2} S_{i j} S_{i j}}=\sigma_{y}
$$

where $\sigma_{e q}$ is the equivalent stress, $\sigma_{y}$, is the yield stress in uniaxial tension and $S_{i j}$ is the deviatoric stress. The plastic strain resulting from material yielding is determined from the Prandtl Reuss flow rule. For each finite time step, the increment of plastic strain, $\Delta \varepsilon_{i j}^{p}$, is given by

$$
\Delta \varepsilon_{i j}^{p}=\frac{3}{2} \frac{\Delta \varepsilon_{p}}{\sigma_{e q}} S_{i j}
$$

where,

$$
\Delta \varepsilon_{p}=\sqrt{\frac{2}{3} \Delta \varepsilon_{i j}^{p} \Delta \varepsilon_{i j}^{p}}
$$

The total plastic strain $\varepsilon^{p}$ is then determined from the summation of the incremental plastic strains over the whole stamping process time, $\mathrm{t}=\mathrm{T}$. Therefore, $\varepsilon^{p}$ is given by,

$$
\varepsilon^{p}=\sum_{t=0}^{t=T} \Delta \varepsilon_{p}
$$

In the present paper, Eqn. 5 together with Fig. 3 (material fails at plastic strain $=1$ ) is used as the failure criteria (for through thickness crack) of the backbone during stamping process. That is through thickness crack of backbone occurs when:-

$$
\varepsilon^{p} \geq 1
$$

The simulation time for the stamping process is 0.55 milliseconds and the output are presented in 12 steps.

\section{FINITE ELEMENT MODEL AND BOUNDARY CONDITIONS}

The equipment for the stamping process consists of the punch, blank and the die. The blank size is $1.47 \mathrm{~m}$ by $1.47 \mathrm{~m}$. The final backbone size is $1.25 \mathrm{~m}$ in length, $0.564 \mathrm{~m}$ in height and $0.769 \mathrm{~m}$ base width. During the process, the blank (flat sheet metal) is placed in between the punch and die. The punch is then moved towards the fixed die pressing the blank to take up the shape of the punch and die. The elements used for the blank, die and punch are 4 nodes rectangular elements. The die and punch are considered to be rigid body and the blank is elastic plastic with stress strain behaviour as that of Fig. 3. Friction exists between punch and blank and between blank and die. These are assumed the same value and represented by Coulomb friction coefficient. The value of the friction is given in Table 1. At the completion of the stamping process, total of 189171 elements for backbone with 3 ribs and 189293 elements for the backbone with 5 ribs were used. In the present work, backbone with 3,4 and 5 ribs 
were analysed. These are shown in Figs. 4, 5 and 6 respectively. The CAD model were developed using CATIA ${ }^{\circledR}$ software, the mesh generation were done by using Hypermesh $^{\circledR}$, and solutions were performed by LSDYNA ${ }^{\circledR}$ software. The mesh and arrangement of the punch, blank and die is shown in Fig. 7. During the stamping process, the punch moved towards the fixed die.

In the fabrication work, the die and punch were made of soft tooling steel and their geometry profiles are the same as that of the backbone. The stamping force of $100 \mathrm{kN}$ were used. The backbone was examined for the existence of visible through thickness crack.

\section{RESULTS AND DISCUSSION}

The main parameters being used in the analysis are the effective von Mises stress, the effective plastic strains and percentage of thickness reduction. The main focus is on the regions around the ribs since these regions were found to be more prone to failure due to tearing. The fringe patterns for the effective von Mises stress, the effective plastic strains and percentage of thickness reduction for backbone with 5 ribs are shown in Figs. 8,9 and 10 respectively. For backbones with 3 and 4 ribs, the pattern is similar except for the numerical values. From Figs. 8,9 and 10, it can be seen that maximum values occurs on the side wall of the ribs. In these locations, maximum stretching of the material occurs resulted in high plastic strains. Through thickness crack of material occurs when the stretched material plastic strains exceeds the maximum values as given by Eqn. 6 .

The variation of effective plastic strain and effective thickness reduction with stamping time, $\mathrm{t}$, for all backbone considered are shown in Fig. 11 and Fig. 12 respectively. From Fig. 11, it can be seen that, the plastic strains are initially zero until stamping time of $\mathrm{t}=0.015 \mathrm{~ms}$. From this moment until $\mathrm{t}=0.045 \mathrm{~ms}$, plastic strain started to increase linearly with $t$ and at $t>0.045 \mathrm{~ms}$, the plastic strain increases rapidly up to the completion of stamping process at $\mathrm{t}=0.056 \mathrm{~ms}$. The time for these events are the same for each of the backbones analyzed. Therefore it can be said that the process is stable and not dependent on the types of backbone. Comparing the development with the stress strain behavior of the material, it can be said that for $\mathrm{t}=0 \mathrm{to} t=0.015 \mathrm{~ms}$, elastic deformation occurs. For $\mathrm{t}=0.015$ to $\mathrm{t}=0.045 \mathrm{~ms}$, the ribs started to develop and the material is in the perfectly plastic part of the curve and finally for $t>0.045 \mathrm{~ms}$, the material is in the plastic hardening region until completion of stamping process. The backbone where effective plastic strain reaches a value more than 1.0, through thickness crack will occur. From Fig. 11, we can say that backbones with 4 and 5 ribs will fail whereas backbone with 3 ribs is unlikely to fail due to excessive plastic straining.

The variation of effective plastic strains and thickness reduction of the backbone ribs with number of ribs are shown in Fig. 13. It can be seen that both the effective plastic strains and thickness reduction increases almost linearly with number of ribs. From Fig. 13 , the conclusion that can be made is that the backbone with 4 and 5 ribs fails with through thickness crack due to excessive plastic straining.

In the fabrication of backbone with 5 ribs ( 3 ribs on one end and 2 ribs on the other), a stamping process was used with soft tooling. It was found that failure in the form of 
through thickness crack occurs in the vicinity of the ribs as shown in Fig. 14. It can be clearly seen that, the failure occurs on every rib and almost on the same sides. The size of the through thickness crack is large and little necking occurs. The location of the crack coincides with the maximum plastic strain as predicted by the finite element analysis results. Therefore, it can be said that the failure that occurs in the fabrication of backbone with 5 ribs is due to plastic strain and the criteria given by Eqn. 6 can be used to predict through crack for backbone stamping.

\section{CONCLUSION}

The objectives of the work have been achieved. Finite element method has been successfully used to predict failure of front platform backbone made of elastic plastic material with plastic brittle failure during stamping process. From the results obtained and presented, the following conclusions can be made:-

1. Backbone with 3 ribs design is suitable to be fabricated using stamping process.

2. Maximum plastic strain criteria can be used to predict through thickness crack part of components made of elastic plastic material with plastic brittle failure and fabricated using stamping process.

These results presented can be used as a suitable guide for automotive body design especially for Natural gas vehicle.

\section{ACKNOWLEDGEMENT}

The authors would like to thank Ministry of Science, Technology and Innovation, Malaysia, for the research grant, Proton and Universiti Putra Malaysia for their collaboration, help and assistance in conducting the research and the preparation of the paper.

\section{REFERENCES}

[1] Halderman, J.D., Mitchell, C.D. Automotive Chassis System, Prentice Hall Multimedia Series, New Jersey, (2000).

[2] Reid, J.D., "Crashworthiness of Automotive Steel Midrails: Thickness and Material Sensitivity", J. of Thin-Walled Structures, Vol. 26, No. 2, pp. 81-103, (1996).

[3] Sahari, B.B., Norwazan, A.R., Hamouda, A.M., Khalid, Y.A., Wong, S.V., "The Effect of Bulge Height and Length on the Lateral Crash Behaviour of Front Platform of a Compressed Natural Gas Vehicle", Int. J. Vehicle Safety, Vol. 2, No. 3, pp. 278-287, (2007).

[4] Livatyali, H., Ergeldi, M. M., "Design of Over-Crown In Sheet Metal Stamping Using Finite Element Method", Journal of Material Processing Technology, Vol. 173, Issue 1, pp. 14-20, (2006).

[5] Yu-ping LI, Li-qun ZHOU, Yi-chun ZHOU, "Elastic-Plastic Solution To Stamping Thin Strip On Elastic Foundation", Transaction of Nonferrous Metals Society of China, Vol. 16, Issue 2, pp. 339-345, (2006).

[6] Du Ting, Liu Yuqi, Zhang Zhibing, Li Zhigang, "Fast FE Analysis Systems For Sheet Metal Stamping - FASTAMP", Journal of Material Processing Technology, Articles in Press, (2007). 
[7] Khelifa, M., Oudjene, M., Khennane, A., "Fracture In Sheet Metal Forming: Effect Of Ductile Damage Evolution", Computers \& Structures, Vol. 182, Issue 1-3, pp. 205-212, (2007).

[8] Huang, Y., Lo, Z.Y., Du, R., "Minimisation Of The Thickness Variation In Multi Step Sheet Metal Stamping", Journal of Material Processing Technology, Vol. 177, Issue 1-3, pp. 205-212. (2006).

[9] Logue, B., Dingle, M., Duncan, J.L., "Side Wall Thickness In Draw Die Forming", Journal of Material Processing Technology, Vol. 182, Issue 1-3, pp. 191-194, (2007).
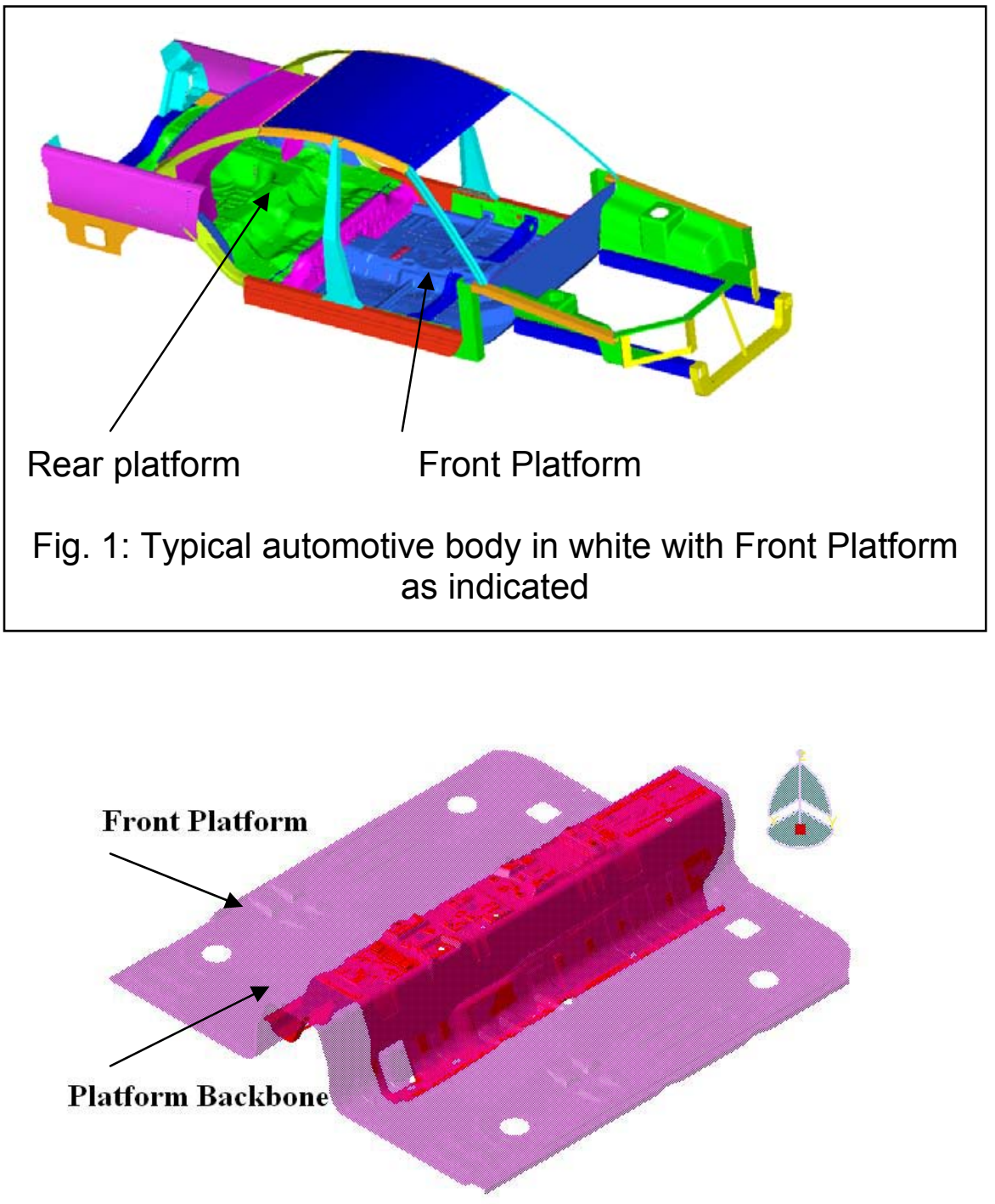

Fig. 2: Detail construction of Front Platform with backbone. 


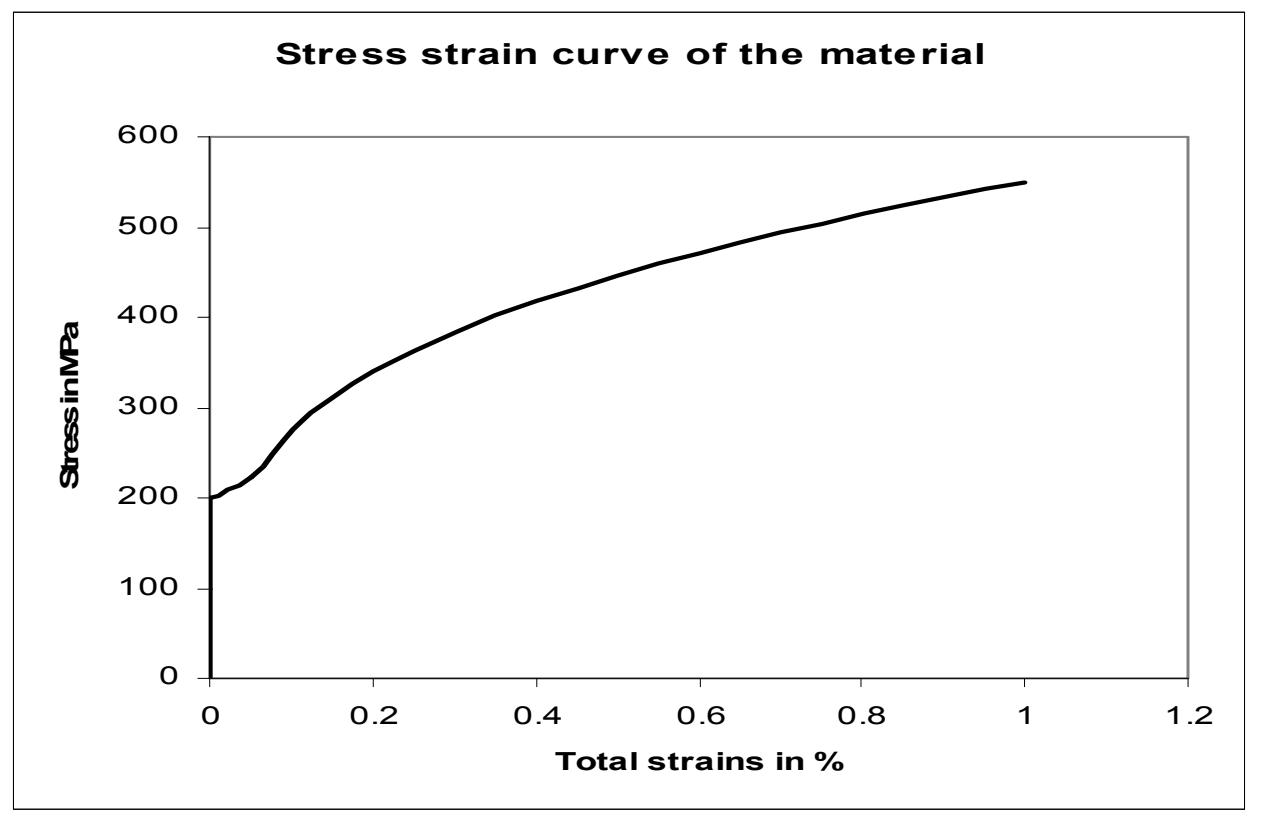

Fig. 3: Stress strain behaviour of steel used to make the backbone.

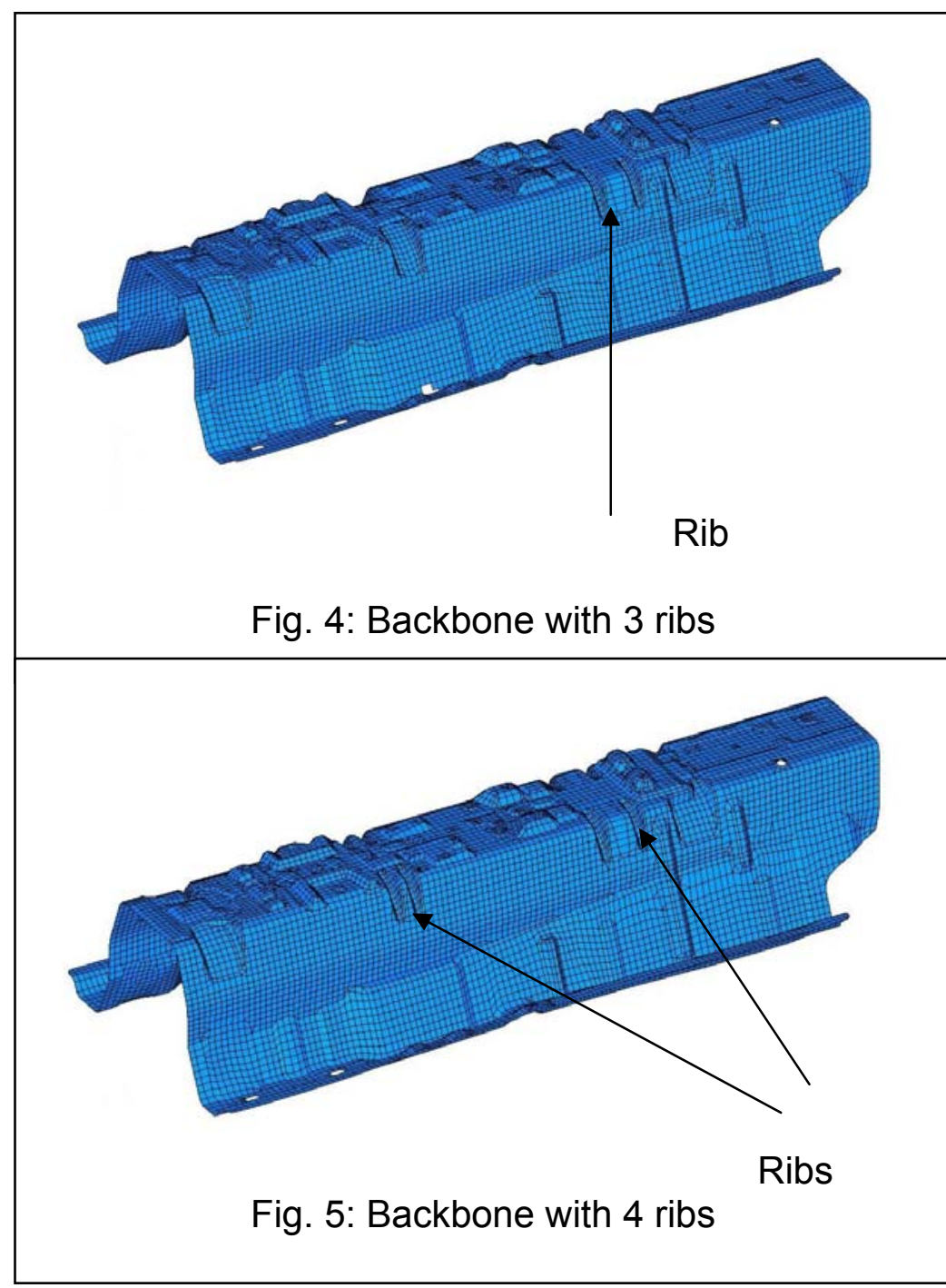



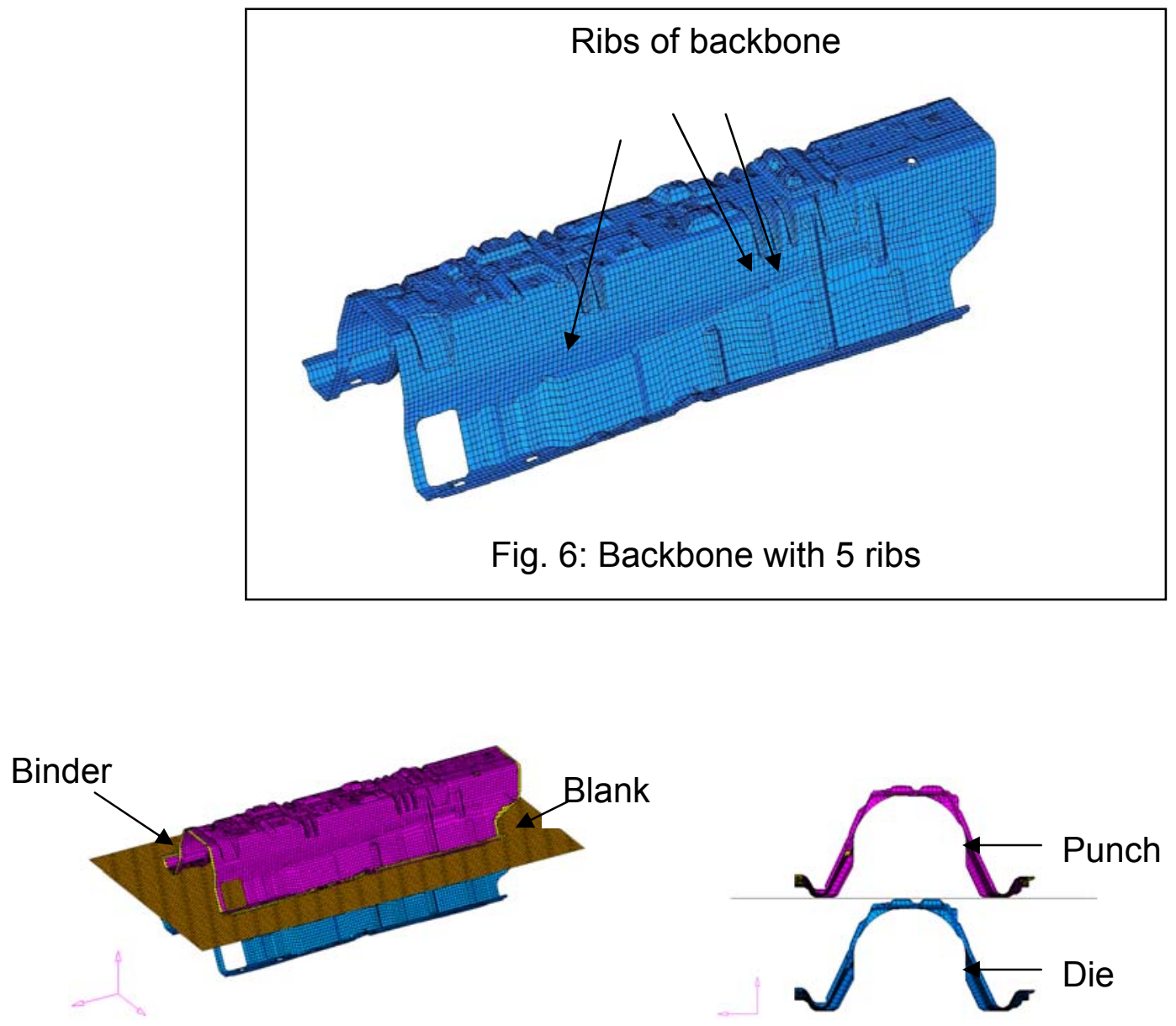

Fig. 7: Binder, blank, punches and dies profile for backbone with 5 ribs.

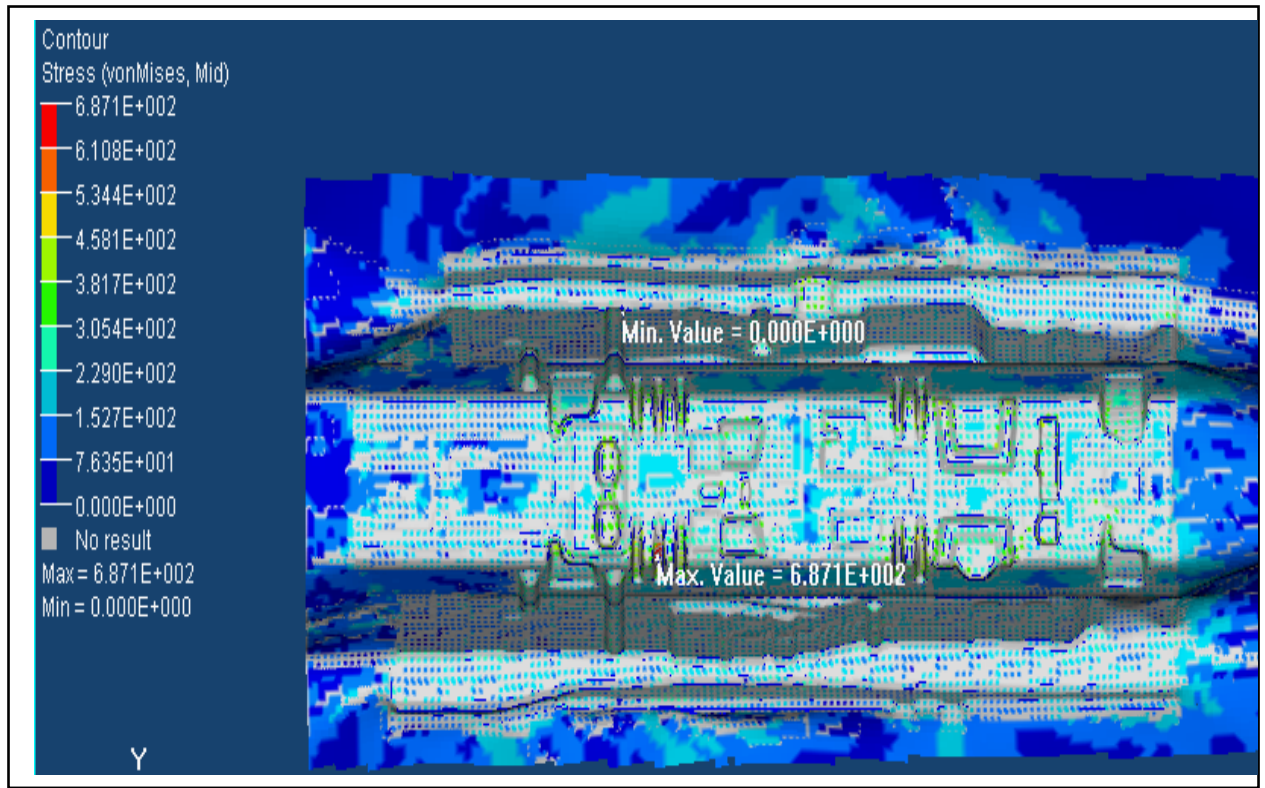

Fig. 8: Von Mises stress results for backbone with 5 ribs. 


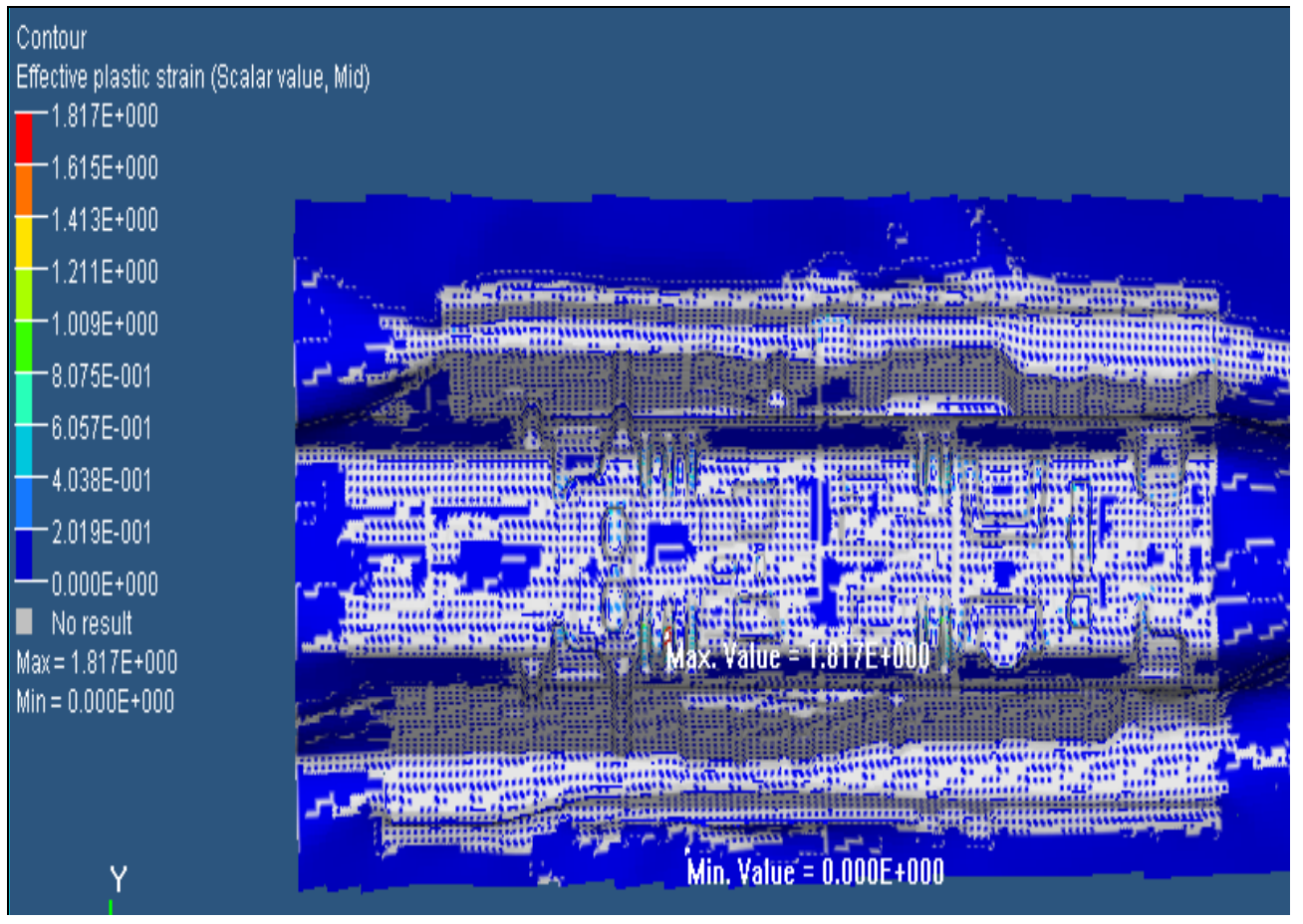

Fig. 9: Effective plastic strains for backbone with 5 ribs.

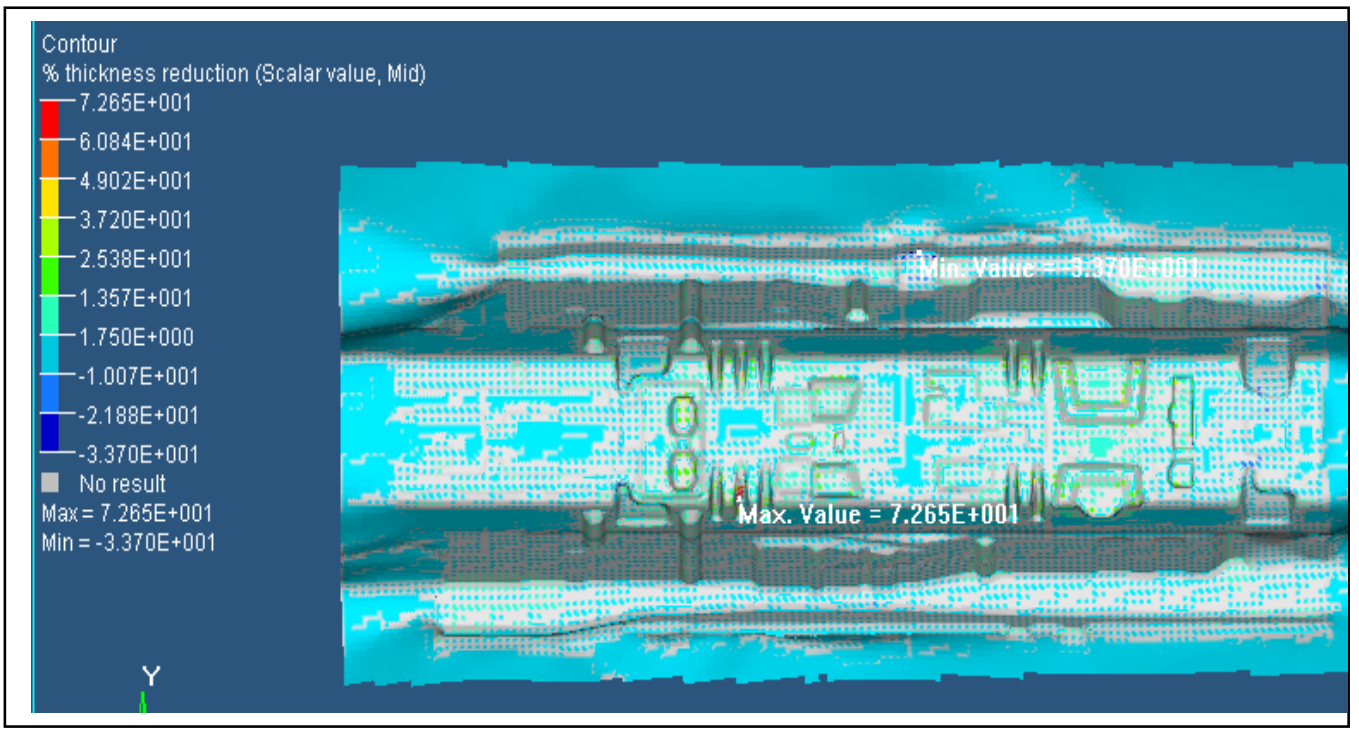

Fig. 10: Percentage thickness reductions for backbone with 5 ribs. 


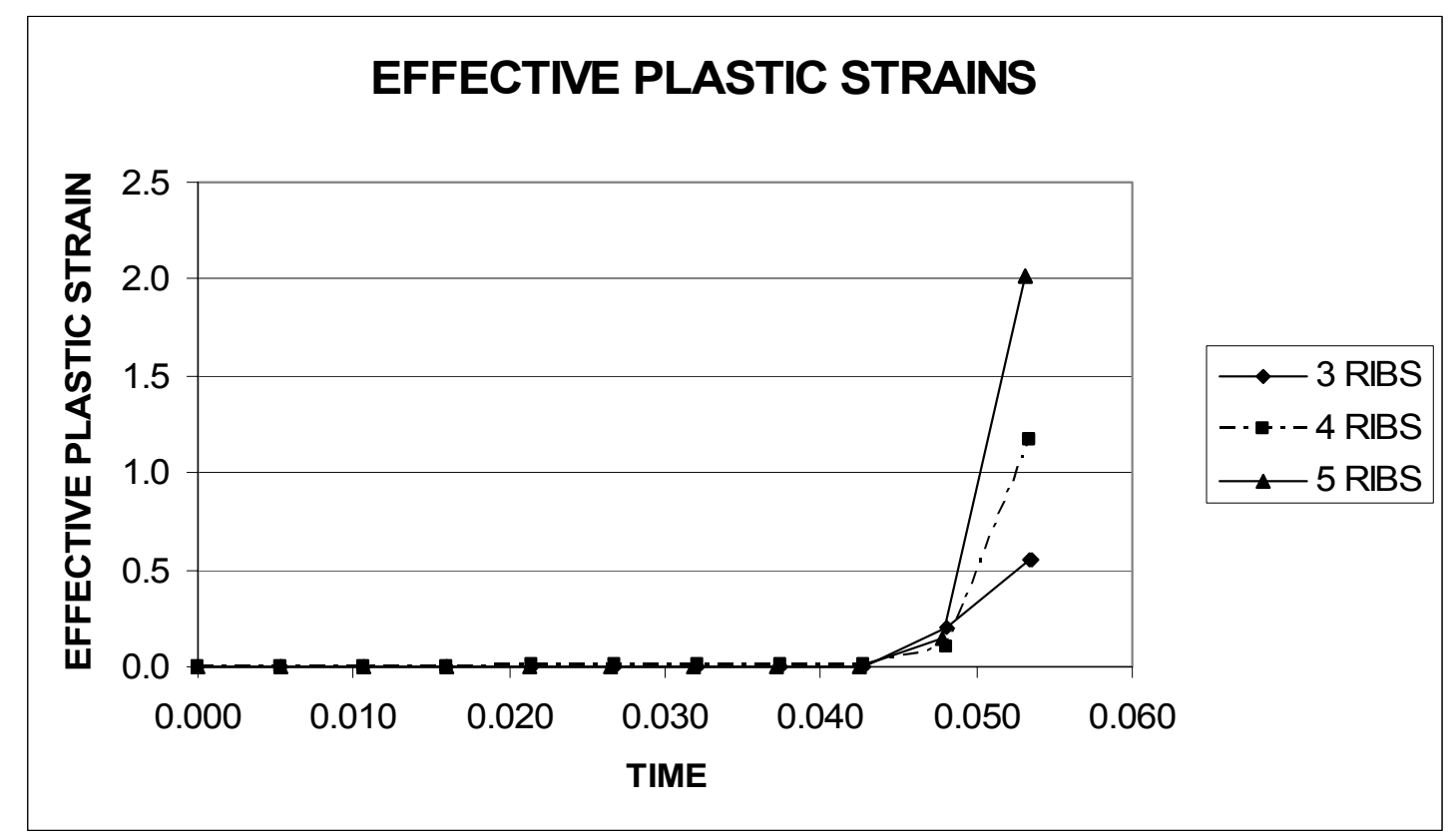

Fig. 11: Variation of effective plastic strain with time

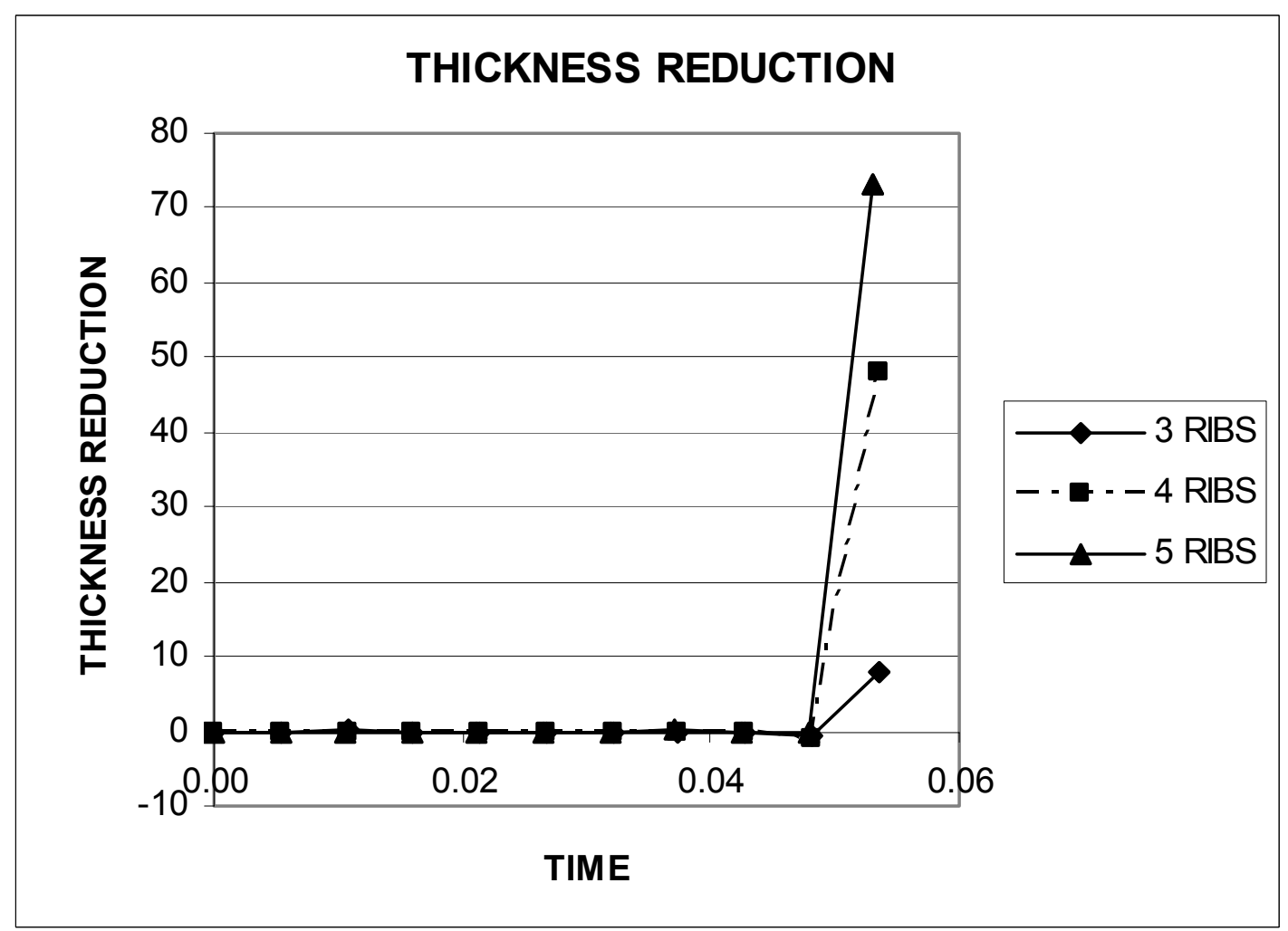

Fig. 12: Variation of effective thickness reduction with time 


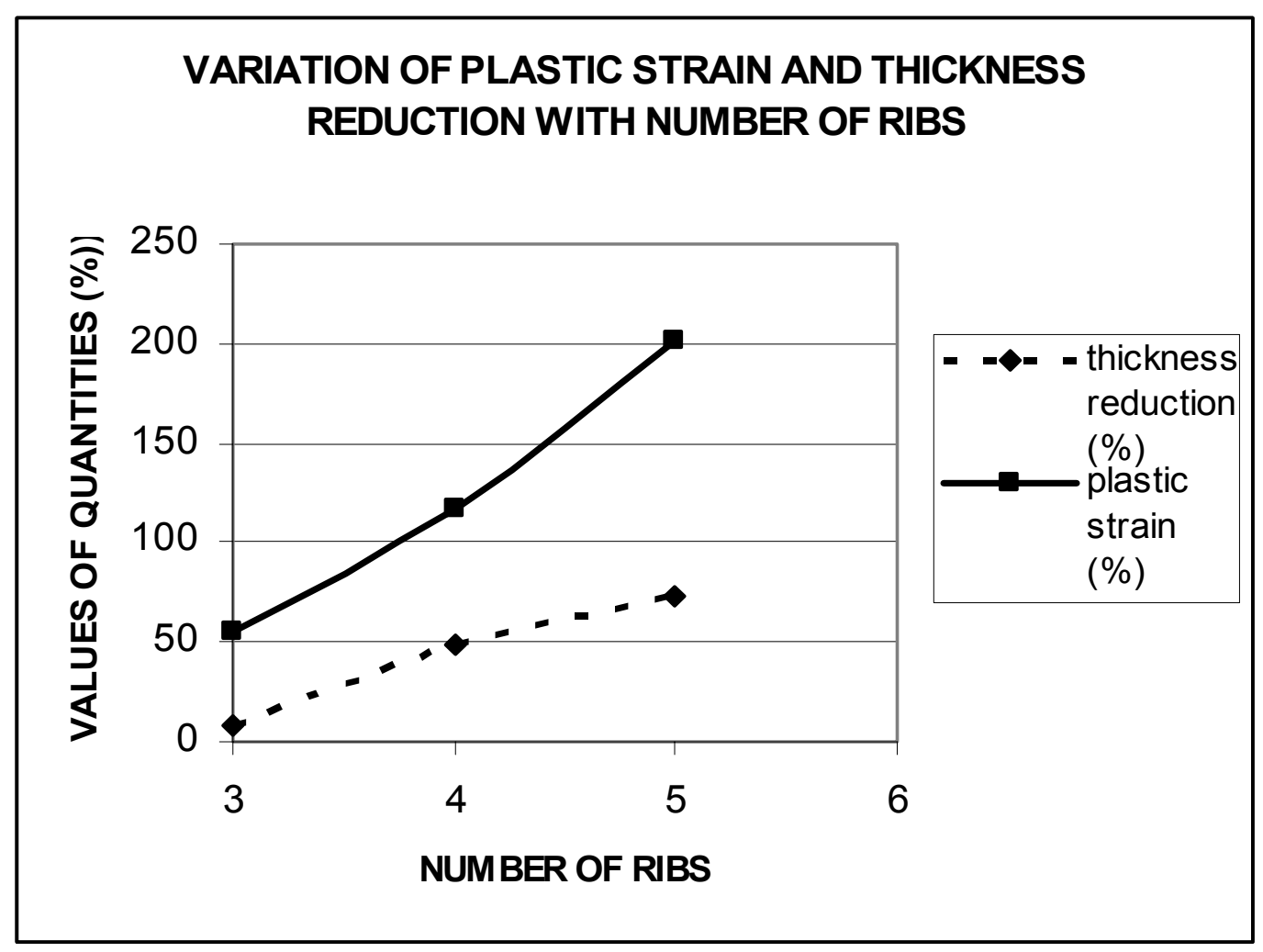

Fig. 13: Variation of effective plastic strain (\%) and thickness reduction (\%) with number of ribs

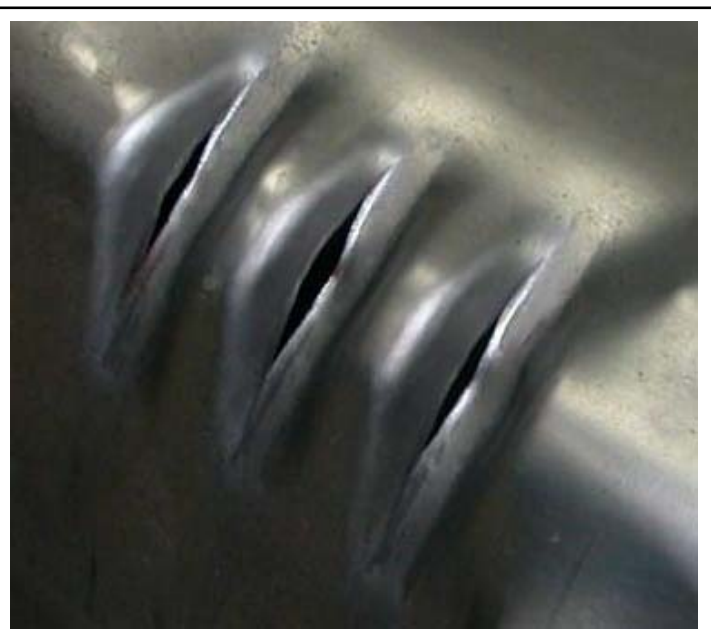

Fig. 14: Backbone with 5 ribs tear-off during experimental stamping process 
Table 1: Material properties and design parameters for platform backbone analysis

\begin{tabular}{|c|l|c|c|c|}
\hline \multirow{2}{*}{ No } & \multirow{2}{*}{ Parameter } & \multicolumn{3}{|c|}{ Backbone model } \\
\cline { 2 - 4 } 1 & $\begin{array}{l}\text { Modulus Young, } \mathrm{E} \\
(\mathrm{GPa})\end{array}$ & 200 & 200 & 200 \\
\hline 2 & Poisson ratio, v & 0.3 & 0.3 & 0.3 \\
\hline 3 & Yield stress, $\sigma_{\mathrm{y}}(\mathrm{MPa})$ & 207 & 207 & 207 \\
\hline 4 & $\begin{array}{l}\text { Coulomb friction } \\
\text { coefficient between } \\
\text { metal sheet and tool }\end{array}$ & 0.15 & 0.15 & 0.15 \\
\hline 5 & Number of ribs, N & 3 & 4 & 5 \\
\hline
\end{tabular}

